\title{
Does Price Matter? How Price Influences Online Consumer Decision-Making
}

\author{
Chiao-Yun Connie Chang ${ }^{*}$ \\ (Coventry University)
}

\begin{abstract}
This research aims to understand how price influences online consumer decision-making and how the Internet influences price when purchasing tourism products through websites in Taiwan. In-depth company and consumer interviews were carried out to gain insights into customer perceptions of price. Companies such as travel agencies, computer reservation systems, hotel reservation systems and academics are embedded in this study in order to capture a holistic picture. The results indicate that the Internet facilitates purchase price consistency within the travel agency; however, there is no guarantee that consumers will definitely obtain the best offer when shopping online. In addition, price seems to be an integral element that appears more than once in the entire decision-making process. Price is not only the first, but also the last element in the decision-making process.
\end{abstract}

Keywords : price, decision-making process, online purchase, consumer behaviour, tourism product, Taiwan

\section{Introduction}

Several researchers have noted that it is helpful for consumers to check a large number of different products and services in pursuit of the best online price (Bakos, 1997; Brynjolfsson and Smith, 2000; Choudhury et al, 1998). Price is always an important attribute in the decision-making process (Herrmann et al., 2007; Lalwani and Monroe, 2005), whether online or offline. The need for a better understanding of the effects of price in the online consumer decisionmaking process is supported by both academic and practical reasons. From a managerial perspective, there are questions about how the Internet impacts upon price competition and consumer perceptions of price, and how online consumers undertake extensive search into different products from various travel agents to obtain better prices on the Internet. From a theoretical perspective, it is necessary to go beyond the extant studies that have focused on the relationships between price and other marketing

The first version of this paper was previously presented at the conference of Academy of Marketing in 2005.

*Visiting Lecturer, Coventry University Business School, Coventry University, UK. factors in decision-making (Monroe, 2003) in order to gain insights into how consumers perceive price and how these perceptions affect purchase decisions.

The primary objective of this paper is to show how price difference impacts upon the online consumer decision-making in Taiwan. It will also investigate how the Internet influences price. The paper begins with a literature review from which a conceptual framework is developed which delineates the factors that influence online consumer decision-making. Next, evidence from both consumers and tourism service providers is used to show how price influences online consumers' choice. Finally, the conclusions drawn from the research are presented.

Key reasons for determining the objects for the present research are as follows. Firstly, during the last decade, the business-to-business (B2C) cyber market in Taiwan has been growing rapidly. Growth in the travel setting has been particularly strong. By 2009, sales in the e-tourism market are estimated to grow to NTD 151 billion. According to the Taiwanese Tourism Bureau, the total number of outbound tourists for 2007 was 8.96 million, an increase of 3.3\% on 2006 and $9.1 \%$ up on 2005. A total of 1.28 million people visited Japan in 2007, 44\% went to China, Hong Kong and Macau, 20.5\% spent their holidays in 
North-east Asian countries (Japan and Korea), 17.5\% went to South-east Asian countries while 10\% visited North America in 2006. Travel related products now account for approximately $48.5 \%$ of the B2C e-market. This suggests that the online market in Taiwan is booming and that more Taiwanese consumers are accepting this as an alternative shopping mode for tourism products.

Next, the benefits of Internet shopping are significant and have changed Taiwanese consumers' lifestyles. For example, Internet shopping provides easy access, time and effort saving, rich information about products and suppliers, instant payment and delivery to consumers' doors. Moreover, online organisations attempt to provide the same service quality that bricks-and-mortar shops offer. Both Internet and online organisations have raised customer expectations about online shopping, which has resulted in customers becoming more demanding in terms of the services they receive. For example, customers now expect an item has all of the expected attributes, is well packaged, delivered on the promised data and exactly as they ordered.

This research aims to extend understanding of consumers' decision-making in relation to services products, by focusing on tourism products. Purchasing an international flight ticket online is relatively expensive compared with buying a $\mathrm{CD}$ or a book. As a consequence, customers are expected to make a greater sacrifice when adopting an online shopping mode for such a product if a poor decision is made. Moreover, customers choose the product based on the information provided on the web page. Such conduct may involve complex decision-making as consumers have to carry out a comparison of different products, service providers and websites. This, indeed, provides a rich context for studying pricing in the online environment.

\section{Literature Review}

Online or offline, price is unquestionably one of the most important extrinsic cues utilised during a consumer's decision-making. Price can be defined as the consumer's perceptual representation or subjective perception of the objective price of the product (Jacoby and Olson, 1977). Zeithaml (1982) proposed that consumers encode and interpret actual price in ways that are meaningful to them. In particular, theories on adaptation level (Helson, 1964) and assimilation-contrast (Sherif et al., 1965) suggest that customers have adaptation level prices or a latitude of acceptable prices for a given product category. Customers judge the actual price of a product to be high, low or fair in comparison with these internal standards (Monroe, 1990). This suggests that it is the perceived product price rather than actual price that affects consumers' product evaluation and choices (Jacoby and Olson, 1977; Zeithaml, 1988).

Price has been a determining factor in consumer choice, playing a more complex role than often attributed to it (Monroe, 1990). Consumers tend to remember information on past and present price and are able to acquire complete information on the attributes of products being considered as options. Consequently, consumers carry out a reasoning process in both online and offline environments, the objectives of which are to minimise the price paid, and, more importantly, to check the quality of the product. In marketing theory, it is still unclear how consumers utilise price information and other cues to judge the value of the offer and the influence this evaluation has on their decision-making (Monroe, 2003).

Grewal et al. (2003) state that price information can be conveyed quickly and unambiguously over the Internet reducing the presence of traditional information asymmetry exists between consumers and suppliers. The Internet enables consumers to compare different products and price information more efficiently and to select the best offer. Sinha (2000) explains that the transparency of Internet pricing stems from (1) the easy availability of product information and therefore, the erosion of "risk premiums" charged by sellers; (2) lower search costs and hence, more efficient buyer search; (3) the ability for buyers to detect the price floor through buyerled pricing and reverse auctions; (4) the dispassionate comparison of prices and features over the Internet as opposed to conventional shopping; (5) the inability of sellers to practise selective pricing; and (6) seller emphasis on building a customer base through lower 
prices and "give-aways." Thus, consumers can search efficiently over the Internet to obtain the lowest prices.

There is an abundance of evidence indicating that consumers are likely to buy at lower prices on websites, but there is also conflicting evidence suggesting that consumers may not actually pay lower prices when buying online. Brynjolfsson and Smith (2000) examined prices of books and CDs sold through the Internet and conventional channels in 1998 and 1999 in the United States. They found that online prices were $9-16 \%$ lower than those in conventional stores. However, Clay et al. (1999) compared prices of books sold by thirteen online and two high street bookstores. They found that prices in online and traditional stores were the same after controlling the homogeneity of book characteristics. Furthermore, Bailey's (1998) study on books, CDs and software sold in both online and offline settings revealed that on average, customers tend to pay more for products when shopping online. Although inconclusive, the findings do seem to indicate that Internet influences the prices paid by consumers. Moreover, there is wide price dispersion in the electronic marketplace. For example, Clements et al. (1999) investigated online markets for airline tickets and found differences in prices across online travel agents as large as $20 \%$, even after controlling for observable product heterogeneity in the United States.

Based on the foregoing review of literature on perceived price and online purchasing, the following key questions are proposed:

(1) How does the price affect purchasing decision of tourism products, in both online and offline shopping?

(2) What is the process of decision-making for online purchasing of tourism products?

(3) In what specific ways does the price affect online purchasing of tourism products at each stage of the entire decision-making process?

(4) How and at which stage do non-price elements affect online purchasing of tourism products?

(5) Does the Internet facilitate uniformity in the purchasing price of tourism products?

(6) Do consumers purchase tourism products at the lowest price when shopping online?

\section{Study Design}

This research used a qualitative research approach. Although most pricing research has been conducted using quantitative approaches such as surveys, experimentation, statistical methods and models and panels (Monroe, 2003), qualitative research method presents detailed descriptions of consumer behaviour that cannot be measured in a quantifiable manner (Malhotra and Birks, 2000).

In-depth, semi-structured, face-to-face interviews, observation such as company visits and secondary materials such as company profiles and company websites were employed for data collection. In-depth interviews were selected because they uncover greater depth in the action of price in the decisionmaking and planning process and enable a fuller understanding of complex consumer behaviour (Malhotra and Birks, 2000). The semi-structured faceto-face interviews were conducted in Mandarin and Taiwanese. Issues covered in the interview questions included price-consciousness, method of website supplier selection, time- and effort-economy, and customer service satisfaction. Data were gathered from both company and consumer sides to discover i) how price influences the consumer decision-making process and ii) the impact of the Internet on this process. Co-operation was obtained from fourteen travel agencies. Marketing managers, IT staff, online travel agents and customer service staff from these agencies were subsequently involved in the research. Computer reservation system (flight tickets) staffs, IT staff from the hotel reservation system and academics were also involved in this qualitative data collection.

Forty interviews were conducted in the travel agencies selected. Seven out of the ten major online travel agencies operating in Taiwan took part in the research. Furthermore, a total of forty-five consumers from the north of Taiwan participated in the study. Eligible participants had to be citizens and permanent residents of Taiwan, aged twenty or over. They also had to have made at least one leisurerelated online purchase in the last twelve months. People in the travel-related business, such as travel 
agents, airline staff, hotel employees, advertisers and market researchers were specifically excluded from these consumer interviews. The average length of the individual interviews, which were recorded and subsequently transcribed, was forty-five minutes. The research fieldwork in Taiwan was divided into two stages, the first taking place in 2004 and the second in 2006. This was done to enable the researcher to investigate any changes in the objects studied resulting from rapid environmental changes such as information technology developments.

\section{Findings and Discussion}

\section{1 Does the Internet facilitate uniformity in the purchasing price of tourism product?}

The company respondents indicated there are three main ways in which customers search for flight ticket prices in Taiwan: these include reading relevant available advertisements both online and offline, contacting familiar travel agents and and/or visiting local travel agencies. The latter two methods are most commonly adopted by individuals who are not comfortable with their computer skills. As an interviewee pointed out, "...we all know that nowadays many people rely on the Internet to gather information, including flight ticket prices. I just do not feel comfortable with this method. I am not good with a computer anyway. I would rather go to travel agencies to ask them for help." Another interviewee also confirmed, "I do not know a lot about computers. I just go to the travel agencies." This result reveals that the computer literacy of an individual plays a role in determining which method is adopted with respect to the researching of flight ticket prices in Taiwan.

The company interviewees further suggested that most people prefer to ask their regular travel agents to search for suitable flight schedules and prices. It is believed that such behaviour is derived from a popular customer assumption that regular travel agents place considerable value on return customers $^{1}$ and may offer better prices to retain their customers. In contrast, from the company's (i.e. travel agency's) perspective, the phenomenon of returning customers demonstrates the attainment of a good level of customer satisfaction and the establishment of a certain degree of rapport between the company and its customers. This finding is in line with the argument put forward by Guo et al. (2009), namely that customer satisfaction cannot be recognised as the sole factor leading to customer retention. In an attempt to show the high quality of their service as well as to initiate a new transaction, these travel agents generally search for two or three suitable products based on the information provided by their consumers. However, it is evident from this study that some customers do not depend solely on a single travel agency for the information. They are likely to approach a number of travel agents both in the same agency and in other agencies in order to secure the best deal. This is due to the varying nature of prices among travel agencies, even for the identical product. Indeed, prices may also vary from agent to agent within the same travel agency in Taiwan. These variations in price have a number of implications for consumers. Taking flight tickets as an example, the same route may be sold at different prices by different salespersons within the same agency. One consumer respondent made the following claim:

"While I was doing some extensive price research, I gathered different price information from several travel agencies. After clarifying all the choices, I decided to contact the first travel agent who had the best offer. When I called again, it was a different travel agent who answered. I asked her about the price of the same route flight ticket on the specific day. However, she quoted another price which was lower than the first travel agent I had contacted before. I wondered whether I should call again to see whether I could get an even lower price from the same travel agency. I did and got the lowest price from the last travel agent for the same flight ticket from the same travel agency......"

A number of the consumer respondents reported similar experiences. The autonomy of individual travel agents to determine prices leads to inconsistent information for the customer although the range in price may not be significant. Such inconsistent information on price within a travel agency tends to motivate price-sensitive customers to visit a number of agents within the same agency 
to obtain the best deal. It is also apparent that pricesensitive customers may well visit several agencies before they feel satisfied with the price offered. The majority of respondents usually search at least five to six travel websites/agencies to check the price of a desired flight ticket. They then make approximately three choices from which to make their final decision. This could mean choosing either the lowest price or the same price with different suppliers. A Chinese saying huoh bii san jia buh chi kuei ${ }^{2}$ (貨比三家不 吃雐), helps explain why respondents visit several websites/agencies and eliminate the prices which do not match their ideal price. The saying indicates a cultural tendency to ensure there are multiple options on which to base their evaluation. In other words, Chinese consumers are culturally taught to adopt a more price-sensitive attitude. Indeed, a study conducted by McKinsey, cited in Kung et al. (2002), supports this claim by showing that most of the online customers in the USA have little interest in searching competing websites. This is because many of them purchase their goods from the first website they visit.

However, a certain degree of change has occurred, which has had an impact on the attitude of the online customers in Taiwan in 2006. Since many travel agencies have become wired over the past years, it is more convenient for consumers to search for price information anywhere and at any time of the day. This has encouraged customers to purchase online. More importantly, in order to save costs incurred by responding to customers' price inquiry phone calls, the travel agencies have also sought to offer consistent prices by removing the autonomy previously enjoyed by individual travel agents. As a consequence, customers are no longer able to negotiate price with travel agents as they have been accustomed to doing. For instance, one consumer respondent stated ".......it is easy to get the product information and when I call the travel agents, I was able to get consistent information, particularly about price." At the same time, half of the company respondents pointed out that the number of telephone calls each day dealing with price comparisons has vastly reduced since online information became available. Most of the calls are now concerned with ordering or consulting issues. This suggests that the Internet is playing a key role in providing consistent price information. Grewal et al. (2003) state that price information can be conveyed quickly and unambiguously over the Internet reducing the presence of traditional information asymmetry exists between consumers and suppliers. The findings support this and demonstrate that the Internet leads to a win-win situation. For example, the Internet saves travel agents time and effort in dealing with telephone calls concerning price comparison which may not be cost-effective to the company. It also enables consumers to obtain up-to-date and consistent price information within seconds in a more efficient and effective manner.

In the current retailing climate there can be price dispersion for each products between brands and between stores in the eTourism market. It takes consumers longer to ascertain price differences between stores than to ascertain brand differences. However, it seems that there is consistency between the online and offline prices. Sinha (2000) argued that the Internet makes costs transparent; however, this research does not fully support this notion. Instead it seems that the travel agencies have retained some power in determining prices, and do not always reveal the true costs to consumers.

There are many factors influence pricing and different companies pursue different approaches. However, there are primarily two pricing strategies. Traditionally, there is a margin range (e.g. 3-5\%) when setting the purchase price for a flight ticket. Some travel agencies simply add five hundred dollars (GBP 9-10) to the cost price (the price purchased from airlines) to give their selling price. Whether this approach is adopted depends on the nature of the business and whether a profit centre system is adopted, where all of the agents share the profits they make. In other cases each travel agent makes individual commission depending on their monthly sales achievements. In such circumstances each travel agent has the right to quote the price under authorisation. Thus one company may set the base line as $1-2 \%$ of the profit margin for consumers to negotiate. Such negotiations may centre discounts for large quantities, loyalty or simply to allow for 
haggling. Indeed, the study's findings support Bailey's (1998) study which suggested that consumers may pay higher prices online than offline. On the other hand, the results are inconsistent with Sinha's (2000) arguments that consumers always benefit from the transparency of Internet pricing.

The issues of how consumers obtain a lower price can be explored from two perspectives. The company respondents suggested that consumers might get a lower price than that quoted online by bargaining with the travel agent face-to-face or over the phone. A few consumer respondents explained that they had a strategy for obtaining lower prices: they first make an online reservation and then attempt to haggle with the online travel agents. In the majority of cases, this would lead to a price reduction of around two hundred dollars (GBP 3-4). While confirming that consumers sometimes acted in this way, some of the company respondents indicated that they did not encourage this approach, particularly as the online price may anyway not be the lowest.

These findings suggest that while there is a consistency between Internet and travel agency prices, the Internet may not necessarily offer consumers the lowest possible price. This is consistent with Tang and Xing's (2001) study in multichannel retailing pricing, which found that the prices for pure online sellers were considerably lower than the prices for the multi-channel retailer. Moreover, Monroe (2003) suggests consumers perceive less risk in buying products that they believe vary little in quality across alternative sellers. If there is little perceived quality variation across sellers, then consumers are more likely to minimise the price paid for such items. This helps to explain why consumers shop around in order to obtain the best deal.

\subsection{Do consumers purchase tourism products at the lowest price when shopping online?}

A travel agency is not a producer, but an intermediary selling flight tickets for airline companies, hotel rooms for hotels, train tickets for rail companies and so on. Such agencies are a source of professional travel advice. For some products, like flight tickets, the customer purchases the right to sit in a specific seat, carry luggage up to a weight allowance, and enjoy onboard refreshments and entertainment. There is no differentiated service among consumers in the same class no matter how much they have paid for their ticket.

In the research, all consumer respondents were fully aware that the quality of the tourism product is controlled and consequently, their primary concern is budget. As a result they may spend between ten minutes and several hours searching online for their ideal price. With an ideal price in mind, some consumer respondents calculated that the price dispersion of the same flight ticket could be NTD 3000-4000 (GBP 50-60), while others suggested they found the range to be fairly small (NTD 500-1000; GBP 10-15). The number of websites visited appears to be a key factor in determining the dispersion experienced. The findings show online consumers seek an acceptable price according to the information at hand and their past experience, but understand that the price they pay will not necessarily be the lowest available Internet price.

\subsection{The process of online purchasing decision-making}

The prices of flight tickets shown on websites depict a nominal value (adult fare). Airport tax, aviation security and fuel levy, air passenger duty, scheduled airline failure administration fee and some hidden costs (travel insurance, service charge per head and delivery charge) are excluded. Normally, travel agents do not charge delivery fees and service charge. Moreover, travel insurance is not a payment option in Taiwan.

One company respondent explained that one way to attract online customers to visit the website is to emphasise the lowest price of their desired product, for example, the nominal value of the flight ticket. When the Web page is entered, there are hundreds of products available, ranging from the cheapest to the most expensive. In addition to economy class flight tickets, details of enhanced economy class and business class are available. The aim of showing three categories is to increase the opportunity for cross-selling. For example, as there is only a marginal difference between economy class and enhanced 
economy class from Taipei to Tokyo during the low season, some passengers who would normally opt for economy class might take the opportunity to upgrade. One company respondent also added that showing three different classes of flight tickets on the same webpage increases competitive advantage for the website, because the price is memorable for consumers doing extant price research.

It is important to consider that the first price which many websites quote is the nominal price, whereas travel agents often start by quoting the all inclusive full fare. The nominal value of the flight is so defined because it does not include additional costs such as airport tax and fuel levy. The level of such additional costs (which include airport tax, aviation security and fuel levy, air passenger duty and scheduled airline failure administration fees) may vary from one airport and airline to another. For example, Heathrow airport tax charged by Cathay Pacific is NTD 5190 (GBP 100). The implication is that for consumers searching online for the best price, it is the nominal price which they see first. This might seem much better value than the all inclusive fare quoted by a travel agent. Thus consumer can forget the difference between the nominal and full fares, opting for what is apparently the cheapest option at this search stage. This is a key reason why websites show only the nominal value and also helps explain why online prices are likely to appear lower than offline.

Tang and Xing (2001) have indicated that online consumers have typically already looked for price savings in the retail market. This is because the price is accessible to the online consumers. The accessibility is determined by the characteristics of the product. In the case of Tang and Xing's research, DVDs were the object of study. The price of DVDs can be relatively easily obtained through certain channels such as from traditional DVD retailers and is less fluid. Therefore, consumers can easily work out the price savings. However, tourism products are different, as there are several factors (e.g. season, departure time and arrival airport) which may cause the price of flight tickets to fluctuate. Information concerning those factors is normally not accessible to the online consumer. Consequently, price savings cannot easily be calculated. As a rule, consumers tend to select the first fare they see online as a standard against which they then judge the price of other offers.

The consumer respondents explained that they not only compare the nominal value online, but also go through the whole online ordering process and calculate the full fare they need to pay, usually going through the calculation process of two websites. Because some websites show a lower nominal value than other websites, airport tax, aviation security and fuel levy, air passenger duty and scheduled airline failure administration fees may be higher in some cases. To sum up, when consumers purchase tourism products online, the nominal value is not the key determinant for making final decision. The consumers will go through the ordering process and discover the final fare they need to pay. They use this "final fare" as the determinant for decision-making.

In this research, majority consumer respondents had more than one online purchase tourism product experience in the last twelve months. They see themselves as smart shoppers who do extensive price research before making purchase decisions. Not only do they go through the calculation process of a couple of travel websites but they also telephone the travel agents to check the price. Thus, it is possible to conclude that online consumers see the nominal value as a reference point while browsing but they tend subsequently also to routinely calculate the full fare. These findings do not support to Monroe's (2003, p. 601) argument which states that the "majority of consumers are not as price sensitive as expected and they do not actively search competing sites before making a purchase decision." To sum up, online consumers are price sensitive. In order to make accurate price comparisons online, consumers tend to gather all information of shipping fees, sales taxes and other service charges before making a purchase decision.

\subsection{In what specific ways does the price affect online purchasing of tourism products at each stage of the entire decision-making process?}

As mentioned above, when browsing websites 
consumer respondents use the price (nominal value) as the first determinant to exclude prices that exceed their budget. Next, they compare the contents of the deal offered in these choices such as itinerary, free baggage allowance, point accumulation and restrictions (e.g. minimum stay, validity, refund). If there are no significant differences in the offers, the full fare price is then the final determinant in deciding which deal to accept. This view has been supported by both the consumer participants and company respondents in this research.

Price plays several roles in consumers' decisionmaking. For example, price can be an indicator of the degree of perceived sacrifice needed to purchase a service and an indicator of the level of quality. A higher perceived price leads to higher perceived quality and consequently to a greater willingness to buy. At the same time, the higher perceived price represents a monetary measure of what must be sacrificed to purchase the service, leading to a reduced willingness to buy. The cognitive trade-off between perceptions of quality and sacrifice results in the perceptions of value which were observed by Dodds et al. (1991). Although previous research indicates the relationships between price and other factors (i.e. quality, sacrifice and value), none of this research explicitly indicates the stage at which price intervenes in the consumer's decision-making. In this research, findings suggest that price plays a pivotal role at the beginning and final stages of consumers' decision-making. Specifically, customers search all relevant product or service information (e.g. price, brand, offerings) in order to make a preliminary selection of several possible options in the search for information stage. In general, customers may use price as a simple reference to skim the unwanted offers from the current market. They then keep some options which meet their criteria. Customers compare and contrast these options thoroughly and based carefully on their needs and preferences. For example, customers may choose some promoted products or services which may include a number of use restrictions (e.g. can only fly with certain scheduled flights or transit only with no stop over). It may result in greater financial loss if customers do not pay attention to these terms and conditions.
Finally, if the offerings of two or three products or services appear identical, customers may choose the product or service which is cheaper. Briefly stated, price is not only the first, but also the final factor used by customers to make their purchase decisions. This is a remarkable finding in the pricing literature and further examination is needed.

\section{Conclusion}

This study has used in-depth company and consumer interviews to explore the extent to which price influences online consumer decision-making when purchasing a tourism product. The findings indicate that there is wide online price dispersion in the service industry. The price dispersion specific to the travel agency has recently been reduced, lessening the confusion felt by consumers when they contact travel agents in the traditional way. Internet purchase prices have generally been shown to be consistent with those offered by travel agencies, so consumers may not get the best offer if shopping online. Online consumers are aware of this as they make their purchase decision, apparently preferring to opt for a price acceptable in the prevailing conditions. The results also indicate the role that price plays in the consumer decision-making. When browsing websites consumers use price as the first determinant to filter out prices exceeding the perceived acceptable range. At the evaluation stage, it appears that price is the final determinant in the decision-making.

This paper contributes to the wealth of marketing literature in several ways. Firstly, the results of the current study make a contribution to the pricing literature by elaborating the role of price in the prepurchase evaluation of alternatives stage. Previous studies suggest that customers use extrinsic cues such as price, quality and brand image to determine the product or service at the evaluation stage. However, very little evidence further suggests how customers use price as a filter to eliminate those products or services that lure them beyond their comfort zone and to make their final purchase decision if two or three products or services are virtually identical. This shows that price is a relatively more powerful factor than quality, brand 
image or store image when making comparisons. Next, it contributes to the marketing theory pertaining to the price and decision-making process by identifying the timing of the price that emerges in the entire decision-making process. The study also contributes to marketing theory in terms of price research and culture diversity by highlighting the crucial impact of culture on consumers' attitudes towards price.

Since price is central to consumers decisionmaking, it is an important area to understand for practitioners seeking to influence customers' buying decisions. Customers have recently become more likely to buy goods or services online on the basis of low price and purchase convenience. In particular, increasing numbers of online organisations offer guarantees that their prices are the lowest in the market and are willing to compensate consumers in the event of that not being the case. However, low price and convenience are not sufficient on their own to win customers over, as website presence, products and low prices can easily be imitated. Due to the global financial crisis, customers pay more attention to what they have paid for, and low price signals or advertisements are quick to catch their eye. Therefore, offering the most economical price to their customers seems to be the best practice in this period to avoid losing market-share. If managers understand the impact of price on the information and pre-purchase evaluation stage, they will be able to exploit the distinct role of the price factor, emphasise additional benefits (e.g. service quality) and influence customers' willingness to buy.

\section{Notes}

${ }^{1}$ In Taiwan, a travel agent's performance is measured by the number of customers $\mathrm{s} /$ he has.

2 This saying translates into English as: in order to ensure one can get the best bargain when purchasing a good, it is better to go to at least three different shops to compare the price and condition of the good before buying it. Here, three means 'many' in the Chinese context.

\section{References}

Bakos, Y. J. 1997 Reducing buyer search costs: Implications for electronic marketplaces.
Management Science, 12(43), 1676-1692.

Bryjolfsson, E. \& Smith, M. D. 2000 Frictionless commerce? A comparison of internet and conventional retailers. Management Science, 4(46), 563-585.

Choudhury, V., Hartzel, K. S., \& Konsynski, B. R. 1998 Uses and consequences of electronic markets: An empirical investigation in the aircraft parts industry. MIS Quarterly, 4(22), 471-508.

Clay K., Karishnan. R., Wolff, E. \& Fernandes, D. 1999 Retail strategies on the web: Prices and non-price competition in the online book industry. Working Paper, Carnegie-Mellon University.

Clemons, E. K., Hann, I-H., \& Hitt, L. M. 1999 The nature of competition in electronic markets: An empirical investigation of online travel agent offerings. Working Paper, Wharton School.

Grewal, D., Iyer, G. R., Krishnan, R., \& Sharma, A. 2003 The Internet and the price-value-loyalty Chain. Journal of Business Research, 5(56), 391-398.

Guo, L., Xiao, J. \& Tang, C. 2009 Understanding the psychological processes underlying customer satisfaction and retention in relational service. Journal of Business Research, 62(11), 1152-1159.

Helson, H. 1964 Adaptation-level theory. New York: Harper and Row.

Herrmann, A., Xia, L., Monroe, K. B. and Huber, F. 2007 The influence of price fairness on customer satisfaction: An empirical test in the context of automobile purchases. Journal of Products \& Brand Management, 16(1), 49-58.

Jacoby, J. \& Olson, J. C. 1977 Consumer response to price: An attitudinal information processing perspective. In Y. Wind \& M. Greenberg (Eds.). Moving ahead in attitude research, 73-86. Chicago: American Marketing Association.

Kung, M., Monroe, K. B. \& Cox, J. L. 2002 Pricing on the Internet. Journal of Product \& Brand Management, 11(5), 274-287.

Lalwani, A. K. and Monroe, K. B. 2005 A reexamination of frequency-depth effects in consumer price judgments. Journal of Consumer Research, 23(3), 480-485.

Lin, D-F. 2003 E-business in travel agency. Taipei: Yang-Chih Book Co., Ltd. 
Malhotra, N. K. and Birks, D. F. 2000 Marketing research: An applied approach, European Edition. Essex: Pearson Education Limited.

Monroe, K. B. 1990 Pricing: Making profitable decisions, $2^{\text {nd }}$ Edition, New York: McGraw-Hill.

Monroe, K. B. 2003 Pricing: Making profitable decisions, $3^{\text {rd }}$ Edition, New York: McGraw-Hill.

Sherif, C., Sherif, M. \& Nebergall, R. E. 1965 Attitude and attitude change. Philadelphia: Saunders.

Sinha, I. 2000 Cost transparency: The Net's real threat to prices and brands. Harvard Business Review, 3(78), 43-50.

Suri, R., Long, M. \& Monroe, K. B. 2003 The impact of the Internet and consumer motivation on evaluation of prices. Journal of Business Research, 5(56), 379-390.

Tang, F-F. \& Xing, X. 2001 Will the growth of multichannel retailing diminish the pricing efficiency of the web? Journal of Retailing, 3(77), 319-333.

Zeithaml, V. A. 1982 Consumer response to instore price information environment. Journal of Consumer Research, 4(8), 357-369.

Zeithaml, V. A. 1988 Customer perception of price, quality and value: A mean-end model and synthesis of evidence. Journal of Marketing, 3(52), 2-22.

(Received September 22, 2009 Accepted December 17, 2009) 